Article

\title{
Influence of Extrusion Temperature on the Aging Behavior and Mechanical Properties of an AA6060 Aluminum Alloy
}

\author{
Nadja Berndt, Philipp Frint * (1) and Martin F.-X. Wagner \\ Institute of Materials Science and Engineering, Chemnitz University of Technology, Erfenschlager Str. 73, \\ 09125 Chemnitz, Germany; nadja.berndt@mb.tu-chemnitz.de (N.B.); \\ martin.wagner@mb.tu-chemnitz.de (M.F.-X.W.) \\ * Correspondence: philipp.frint@mb.tu-chemnitz.de; Tel.: +49-371-531-38218
}

Received: 12 December 2017; Accepted: 9 January 2018; Published: 12 January 2018

\begin{abstract}
Processing of AA6060 aluminum alloys for semi-products usually includes hot extrusion with subsequent artificial aging for several hours. Processing below the recrystallization temperature allows for an increased strength at a significantly reduced annealing time by combining strain hardening and precipitation hardening. In this study, we investigate the potential of cold and warm extrusion as alternative processing routes for high strength aluminum semi-products. Cast billets of the age hardening aluminum alloy AA6060 were solution annealed and then extruded at room temperature, 120 or $170{ }^{\circ} \mathrm{C}$, followed by an aging treatment. Electron microscopy and mechanical testing were performed on the as-extruded as well as the annealed materials to characterize the resulting microstructural features and mechanical properties. All of the extruded profiles exhibit similar, strongly graded microstructures. The strain gradients and the varying extrusion temperatures lead to different stages of dynamic precipitation in the as-extruded materials, which significantly alter the subsequent aging behavior and mechanical properties. The experimental results demonstrate that extrusion below recrystallization temperature allows for high strength at a massively reduced aging time due to dynamic precipitation and/or accelerated precipitation kinetics. The highest strength and ductility were achieved by extrusion at $120^{\circ} \mathrm{C}$ and subsequent short-time aging.
\end{abstract}

Keywords: aluminum alloy; cold extrusion; warm extrusion; severe plastic deformation (SPD); dynamic aging; precipitation hardening

\section{Introduction}

Aluminum alloys of the 6xxx series, which are prominent examples for many structural applications in automotive and aviation industry, are usually processed by hot extrusion. Their mechanical properties are then adjusted by a subsequent heat treatment since the alloying elements $\mathrm{Mg}$ and $\mathrm{Si}$ enable an effective precipitation hardening the low flow stress at elevated temperatures allows for high extrusion ratios (ratio of cross sectional area of the billet versus the extrudate) as well as pressing speeds. For processing of the AA6060 aluminum alloy, which has a very high formability, and therefore is one of the most commonly used aluminum alloys, the homogenized billets are typically extruded at temperatures between 400 and $500{ }^{\circ} \mathrm{C}$, followed by water or air quenching [1]. Enhancing the strength of the extruded semi-products by artificial aging at 160 to $180{ }^{\circ} \mathrm{C}$ takes up several hours. One effective, alternative processing strategy that considerably reduces aging times and additionally increases strength is cold deformation of the as-solutionized material. The high densities of dislocations and vacancies produced by large plastic strains ensure effective strain hardening; they also increase the diffusion rates of solute atoms, and can therefore significantly accelerate precipitation kinetics [2,3]. In case of severe plastic deformation (SPD), e.g., by equal-channel angular pressing (see e.g., [4-6]) 
or high-pressure torsion, a rearrangement of dislocations into cell walls and subsequently into small and large angle grain boundaries results in the formation of fairly homogeneous ultrafine-grained (UFG) microstructures [7]. At elevated temperatures, partial or complete dynamic precipitation may also occur during SPD [8-11]. The strengthening effect of subsequent artificial aging therefore strongly depends on the amount of applied (equivalent) strain, as well as on the aging temperature. The strengthening effects is, however, often limited: age hardening can be suppressed or even replaced by age softening [12-14].

In our previous study [15], we investigated an unconventional processing technique for the AA6060 aluminum alloy that aimed at combining the benefits of SPD processing (high strength, short aging time) and extrusion (change of shape) by extruding below recrystallization temperature. We characterized two ways of processing that significantly increase hardness and strength when compared to the conventional T6 condition-sequential and simultaneous extrusion and aging, respectively. While the first-room-temperature extrusion and subsequent aging-results in a more homogenous distribution of strength and a slightly higher ductility, the second-extrusion at aging temperature $\left(170{ }^{\circ} \mathrm{C}\right)$-benefits from lower pressing forces and advanced dynamic precipitation.

As none of these strategies fully exploit the potential of combined strain and precipitation hardening, the present study is focused on the optimization of mechanical properties by extrusion at $120{ }^{\circ} \mathrm{C}$, followed by a suitable heat treatment. We compare the microstructural features and aging behavior of the extruded material with the results from our previous study and we show how our optimized processing route allows for the fabrication of rod-shaped semi-products with a homogeneously distributed maximum hardness as well as strength and a reasonable ductility.

\section{Materials and Methods}

The material used in this study is the precipitation hardenable aluminum alloy AA6060, with a chemical composition of $0.5 \mathrm{Si}-0.5 \mathrm{Mg}-0.2 \mathrm{Cu}-0.2 \mathrm{Fe}-$ balance $\mathrm{Al}(\mathrm{wt} \%)$. Billets of the continuous cast material were solid-solution annealed for $3 \mathrm{~h}$ at $530^{\circ} \mathrm{C}$, and then water-quenched to room temperature. Backward-extrusion was carried out in horizontal extrusion press with a maximum press capacity of $8 \mathrm{MN}$. The diameters of the cast billets and of the containers were 107 and $110 \mathrm{~mm}$, respectively. A flat die with an inner diameter of $45 \mathrm{~mm}$ was used, resulting in an extrusion ratio (ratio of billet cross-section area vs. extrudate cross-section area) of about 6.

Three different processing temperatures were selected for extrusion. On the one hand, extrusion was performed at room temperature (RT), which results in maximum strain hardening of the aluminum alloy. On the other hand, extrusion was performed at elevated temperatures of 120 (intermediate temperature- $\mathrm{IT}$ ) and $170{ }^{\circ} \mathrm{C}$ (which corresponds to the conventional aging temperature of this alloy-AT) in order to reduce pressing forces and to promote dynamic precipitation. Because it directly combines two essential processing steps, extrusion at these temperatures presents an economically promising approach. To prevent an excessive temperature increase related to friction and quasi-adiabatic heating, extrusion was carried out at a low ram speed of $18 \mathrm{~mm} / \mathrm{min}$. In addition, Bechem Beruforge 150D, a lubricant that is well suited for cold forming of aluminum [16], was applied to the contact areas between the billets and the die. For AT-extrusion, the billets were heated to $170{ }^{\circ} \mathrm{C}$ in an induction furnace, while the die was heated in a convection furnace prior to processing. The container was held at a temperature of $150{ }^{\circ} \mathrm{C}$ during the entire pressing operation. For IT-extrusion, all processing temperatures (billet, die, and container) were heated to $120^{\circ} \mathrm{C}$. The IT- and AT-extrudates were spray-cooled at the runout of the press.

The aging behavior of the extruded material was studied after artificial aging (performed in a convection furnace at $170{ }^{\circ} \mathrm{C}$, with annealing times ranging from 1 to $6000 \mathrm{~min}$ ) using an automatic hardness tester (KB250BVRZ, KB Prüftechnik GmbH, Hochdorf-Assenheim, Germany). Vickers hardness (HV1) was measured on the longitudinal planes of the extrudates (i.e., planes containing the extrusion direction and a radial direction). Flat specimens for tensile testing were cut along the extrusion direction using wire electric discharge machining (see Figure 1). Quasi-static tensile testing 
was performed at room temperature with an initial strain rate of $10^{-3} \mathrm{~s}^{-1}$ using a Zwick/Roell Z020 universal testing machine with a $20 \mathrm{kN}$ load cell. Strains were measured using a digital image correlation system (GOM GmbH, Braunschweig, Germany).

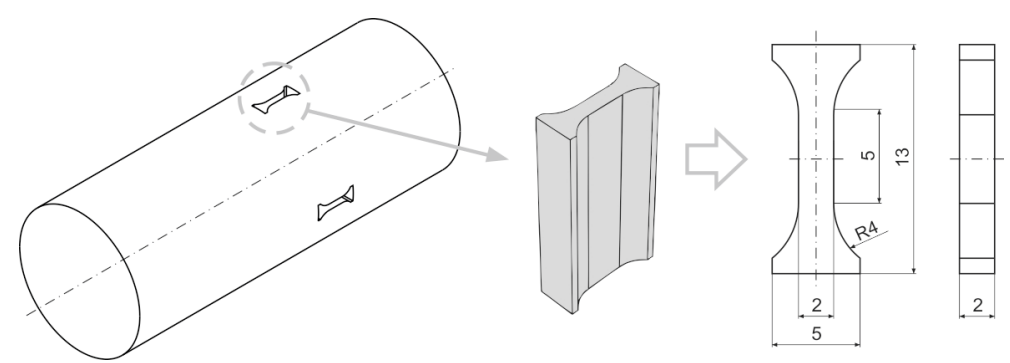

Figure 1. Schematic representation of sample extraction for tensile testing. Flat miniature tensile specimens were cut from the extruded material using wire electric discharge machining.

Samples for microstructural analysis by scanning electron microscopy (SEM) and transmission electron microscopy (TEM) were extracted from the transverse planes at the centers and in the peripheral areas of the extrudates. For electron back-scatter diffraction (EBSD) measurements, the samples were mechanically prepared by a standard grinding and polishing procedure with an additional vibratory polishing step for one hour in aqueous colloidal $\mathrm{SiO}_{2}$ solution. The EBSD patterns were collected with an EDAX detector using a Zeiss Neon 40 field emission scanning electron microscope at an acceleration voltage of $10 \mathrm{kV}$ and with an aperture of $120 \mu \mathrm{m}$. Post-processing included a slight clean-up of the raw data (neighbor confidence index correlation). The TEM samples were mechanically thinned to approximately $80 \mu \mathrm{m}$ followed by twin jet electro-polishing (Tenupol-5, electrolyte: A7, $-32{ }^{\circ} \mathrm{C}$ ). TEM was carried out using a Hitachi H8100 TEM with an acceleration voltage of $200 \mathrm{kV}$.

\section{Results and Discussion}

\subsection{Microstructural and Mechanical Characterization of the as-Extruded Material}

As discussed in detail in our previous study [15], cold and warm extrusion of an AA6060 aluminum alloy results in relatively similar, heterogeneous microstructures that exhibit two characteristic regions: The majority of the extrudate's cross sectional area consists of a microstructure containing both coarse and fine grains that are elongated parallel to the direction of extrusion. Towards the surface, a distinct layer with a width of about $2 \mathrm{~mm}$ is observed. This layer exhibits an (ultra)fine-grained pancake-microstructure, i.e., the grains are elongated parallel to the direction of extrusion, as well as parallel to the circumference of the extrudate [15].

The microstructures of the center areas and surface layers of the as-extruded conditions are shown in Figure 2. The (large angle) grain boundary maps (obtained by EBSD) show a similar microstructure for the center areas (Figure $2 \mathrm{a}-\mathrm{c}$ ), where areas of large grains can be found next to areas containing considerably smaller grains. In the surface layers, a similar bimodal-like microstructure can be observed. However, the overall grain size is much smaller, i.e., areas of fine grains exist next to UFG areas (Figure $2 \mathrm{~d}-\mathrm{f}$ ). The fraction of UFG areas is the highest after RT-extrusion with about $50 \%$ of the area shown in the grain boundary map (Figure 2d). In contrast, the UFG areas of the IT- and AT-extruded materials correspond to only about $20 \%$ of the scanned area (Figure $2 \mathrm{e}, \mathrm{f}$ ). This indicates an earlier stage of the grain refinement process after warm extrusion, which is most likely caused by the more pronounced recovery during extrusion at elevated temperatures. 


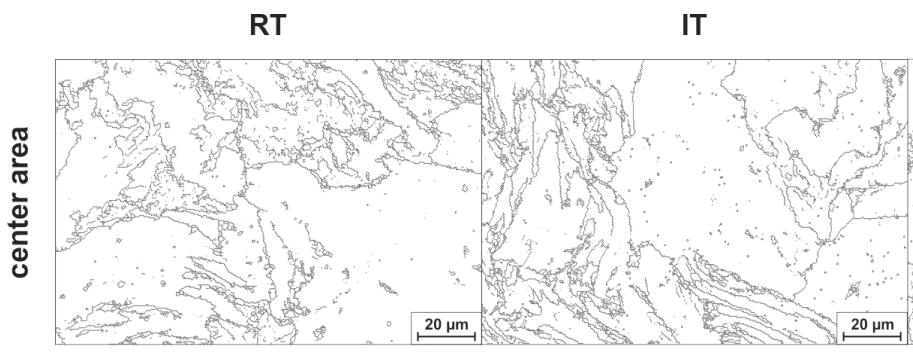

(a)

(b)

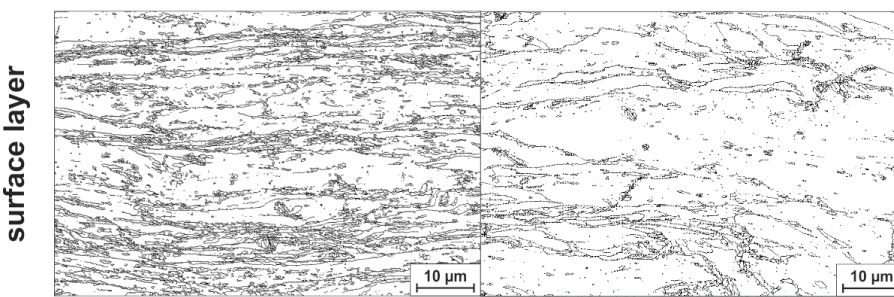

(d) (e)
AT

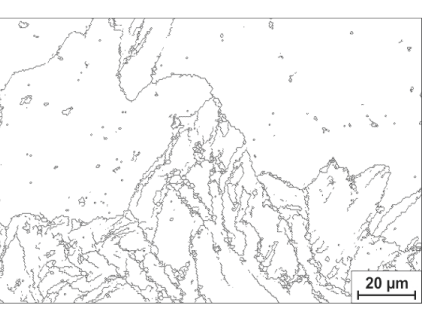

(c)

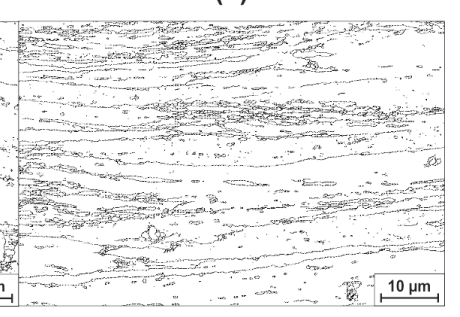

(f)

Figure 2. Microstructure of the center areas $(\mathbf{a}-\mathbf{c})$ and surface layers $(\mathbf{d}-\mathbf{f})$ of the extruded materials. The grain boundary maps were obtained by electron back-scatter diffraction (EBSD) (step size of $500 \mathrm{~nm}$ for the center areas and of $100 \mathrm{~nm}$ for the surface layers) and show the distribution of large angle grain boundaries with a minimum misorientation angle of $15^{\circ}$.

Further differences regarding the microstructure after cold and warm extrusion are shown in Figure 3. The TEM bright-field micrographs were taken from the center areas and surface regions of the three extrudates and illustrate the effect of dynamic precipitation during deformation at elevated temperatures. While no precipitates could be found in the center area or the surface layer of the RT-extruded material (Figure 3a,d), precipitates of varying size were found in both of the regions after IT- (Figure $3 \mathrm{~b}, \mathrm{e}$ ) and AT-extrusion (Figure $3 \mathrm{c}, \mathrm{f}$ ). For extrusion at both 120 and $170^{\circ} \mathrm{C}$, the center areas exhibited small precipitates in the grain interiors (areas marked by dashed white ellipses) and slightly larger ones in the proximity of grain boundaries (see black ellipse in Figure $3 b$ ). Please note that the size of the coherent $\beta^{\prime \prime}$-precipitates is rather low (needle-shaped with several ten nanometers in length and less than ten nanometers in diameter), which makes them difficult to recognize in the TEM micrographs, In the surface layers precipitation often took place in close proximity to the grain boundaries (dashed black ellipses in Figure 3e) and overall larger precipitates-when compared to the center areas-were observed. For AT-extrusion, cuboid-shaped precipitates with a diameter of about $80 \mathrm{~nm}$ were observed in the surface layer (Figure 3f, dashed black circle), which strongly indicates the beginning of over-aging in this region.

In order to characterize the mechanical properties of the extruded materials, Vickers hardness was measured as a function of distance from the extrudates' surfaces (Figure 4). For the RT-extruded material, the lowest hardness occurs in the center area and then increases towards the periphery, corresponding to an increasing amount of plastic deformation. Near the surface layer, starting at a depth of approximately $2-2.5 \mathrm{~mm}$, a sharp increase of hardness is observed; this increase likely results from an additional grain boundary strengthening effect due to the (ultra)fine-grained microstructure. A similar surface layer hardness of about $103 \mathrm{HV}$ was measured for all as-extruded conditions. In contrast to the hardness profile of the RT-extruded material, however, the decrease of hardness towards the center is not as pronounced after IT-extrusion, and the AT-extruded material actually exhibits a slightly increasing hardness from the surface towards the center of the extrudate. Therefore, despite the UFG microstructure that was also observed in its surface layer, a higher hardness could be obtained in the coarser grained center area. This effect is most probably related to the different stages of precipitation in the core when compared to the surface of the AT-extruded material, as also indicated by the microstructural features documented in Figure $3 \mathrm{c}, \mathrm{f}$. 


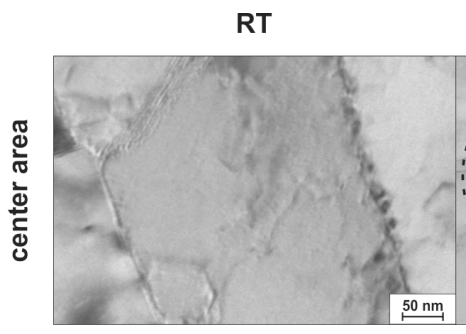

(a)
IT

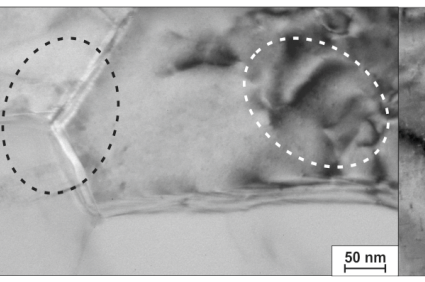

(b)
AT

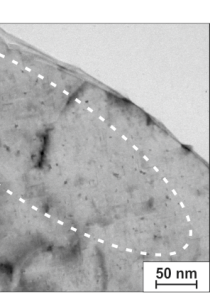

(c)

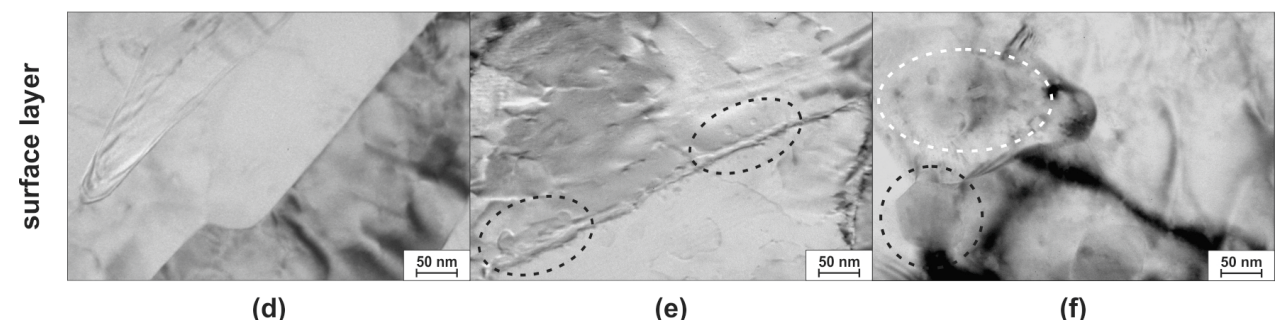

(d)

(e)

(f)

Figure 3. Transmission electron microscopy (TEM) bright-field images taken from the center areas (a-c) and surface layers (d-f) of the extruded material. While room temperature (RT)-extrusion does not initiate dynamic precipitation, precipitates with diameters ranging from a few nanometers up to $80 \mathrm{~nm}$ were found both in the IT- and AT-extruded materials (areas containing precipitates are highlighted by white and black ellipses).

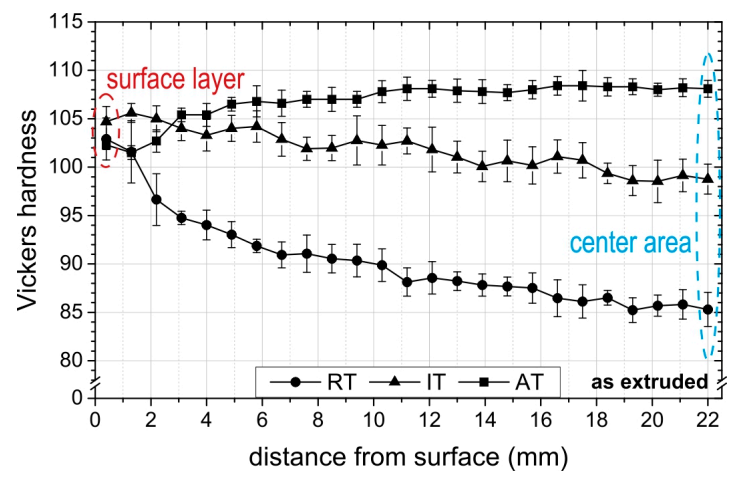

Figure 4. Vickers hardness as a function of distance from surface for the as-extruded materials after RT- (circles), IT- $\left(120^{\circ} \mathrm{C}\right.$, triangles) and AT-extrusion $\left(170{ }^{\circ} \mathrm{C}\right.$, squares). Dashed red and blue ellipses highlight hardness values that represent the surface layers and the center areas, respectively.

\subsection{Aging Behavior of Cold and Hot Extruded Materials}

To study the aging behavior of the surface layers and the center areas, Vickers hardness was measured after aging for different times at $170{ }^{\circ} \mathrm{C}$ (Figure 5). The first data points (at an aging time of $0.01 \mathrm{~min}$ ) represent the first and last points of the hardness distribution curves of the as-extruded conditions, as marked by the dashed red and blue ellipses in Figure 4. Although the initial core hardness (blue curves) differs strongly for the investigated extrusion temperatures, a similar maximum hardness of about 109 to $115 \mathrm{HV}$ can be achieved at aging times that range from 40 to $90 \mathrm{~min}$. In contrast, the three extrudates exhibit a similar initial surface hardness (red curves), which then develops diversely during aging: While it is possible to increase the hardness of the surface layer after IT-extrusion up to $115 \mathrm{HV}$ by artificial aging for about $40 \mathrm{~min}$, age softening occurs after RTand AT-extrusion. In the case of AT-extrusion, the softening effect sets in with the beginning of the additional annealing, which corresponds to the beginning of over-aging, as already discussed on the basis of the TEM micrographs (Figure 3). For the RT-extruded material, hardness remains constant for about $100 \mathrm{~min}$ before significant softening sets in. As discussed in [15], this probably results 
from a dynamic equilibrium of the competing processes of precipitation hardening and softening by temperature-driven recovery. As it is likely to have already recovered during warm extrusion, and because it does not exhibit unusually large precipitates like the AT-extruded material, the surface layer of the IT-extruded material maintains its potential for precipitation hardening.

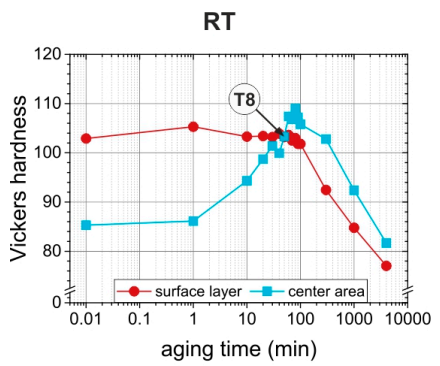

(a)

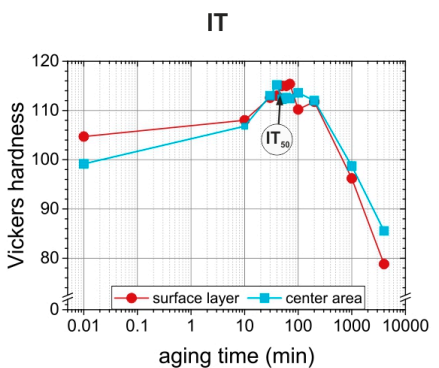

(b)

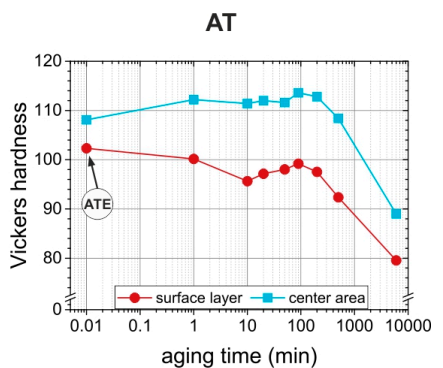

(c)

Figure 5. Vickers hardness plots of the surface layers and the center areas of the extruded materials as a function of aging time at $170^{\circ} \mathrm{C}$ for (a) RT-extrusion; (b) IT-extrusion $\left(120^{\circ} \mathrm{C}\right)$; and, (c) AT-extrusion $\left(170^{\circ} \mathrm{C}\right)$. Material conditions with the highest homogenous hardness ("optimized" material conditions) are marked for all the extruded materials (labels in circles).

\subsection{Microstructural and Mechanical Characterization of Optimized Material Conditions}

On the basis of the hardness data presented in Figure 5, one condition with the highest homogeneous hardness was chosen as "optimized" material for each extrusion temperature: RT-extruded and peak-aged (50 $\mathrm{min}$ at $170{ }^{\circ} \mathrm{C}$; labeled T8 in Figure 5), IT-extruded and aged for $50 \mathrm{~min}$ (labeled $\mathrm{IT}_{50}$ ) and AT-extruded without subsequent aging (as-extruded; labeled ATE). Additional TEM investigations were performed to relate microstructural changes during aging with the documented changes in terms of mechanical properties. TEM analysis of the optimized conditions T8 and $\mathrm{IT}_{50}$ (Figure 6) showed that artificial aging for $50 \mathrm{~min}$ results in finely dispersed precipitates that are responsible for the increased hardness values. Precipitation occurred both in the center areas and in the surface layers, therefore contributing to an improved homogeneity of hardness values, particularly in the RT-extruded material condition.

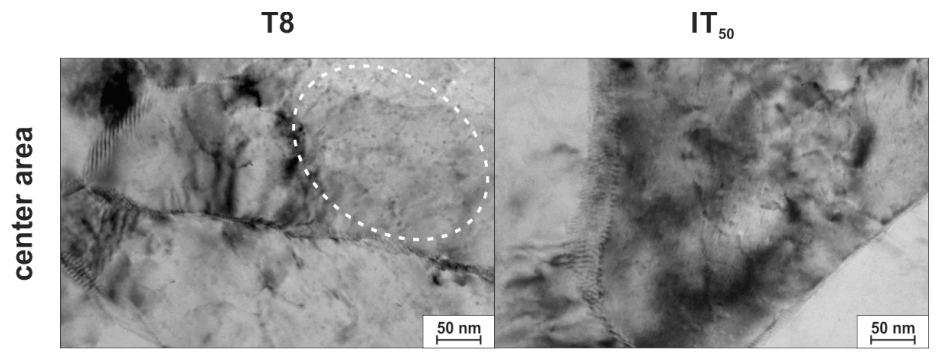

(a)

(b)

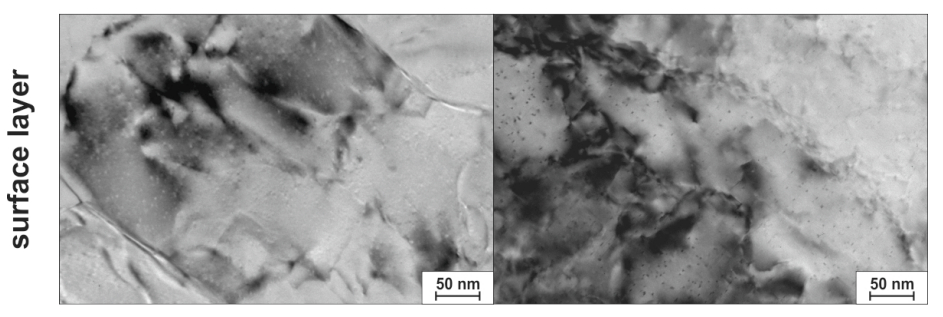

(c)

(d)

Figure 6. TEM bright-field images taken from the center areas $(\mathbf{a}, \mathbf{b})$ and surface layers $(\mathbf{c}, \mathbf{d})$ of the extruded and artificially aged material. Both conditions $\mathrm{T} 8$ and $\mathrm{IT}_{50}$ exhibit very fine precipitates in the center areas as well as in the surface layers. 
The tensile properties were characterized in great detail by examining tensile test data as a function of distance from the extrudate surface. The results are summarized in terms of yield strength (YS), ultimate tensile strength (UTS), uniform elongation (UE), and elongation to failure (ETF) in Figure 7. For the ATE material condition, the evolution of YS is similar to the corresponding hardness curve, with the lowest value near the surface (308 MPa) and increasing values towards the center (>350 MPa). In contrast, the YS of both aged conditions T8 and IT $_{50}$ can be considered constant over the cross section despite the differences in microstructure. As shown in Figure $7 \mathrm{~b}$, the UTS of all the investigated conditions is similarly distributed over the cross section with values increased by about 15 to $20 \mathrm{MPa}$ when compared to the respective YS. The highest UTS of $380 \mathrm{MPa}$ is measured for the IT-extruded and artificially aged material. When compared to the peak-aged $\left(2000 \mathrm{~min}\right.$ at $\left.170{ }^{\circ} \mathrm{C}\right)$ cast material with an UTS of $289 \mathrm{MPa}$, this represents an increase by about $31 \%$. Regarding UE, all conditions exhibit a similar distribution with lowest values near the surface and increased ductility in the center area. The lower ductility in the surface layer is likely to result from the maximum amount of cold work in this region, which leads to a low hardening rate and to early necking of the specimens during tensile testing. The overall somewhat better uniform elongation of the $\mathrm{T} 8$ and $\mathrm{IT}_{50}$ conditions is assumed to result from the additional heat treatment that allowed for a reduction of lattice defects by recovery mechanisms.

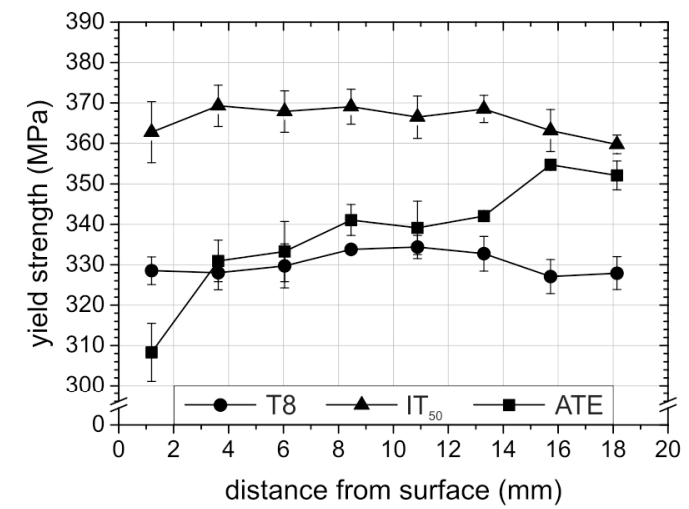

(a)

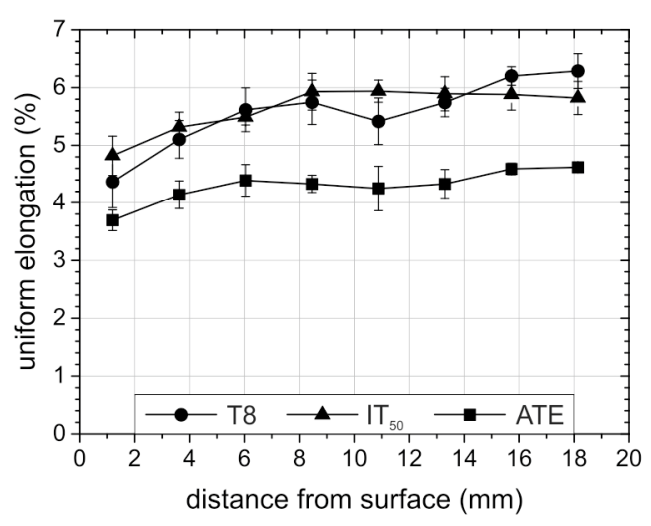

(c)

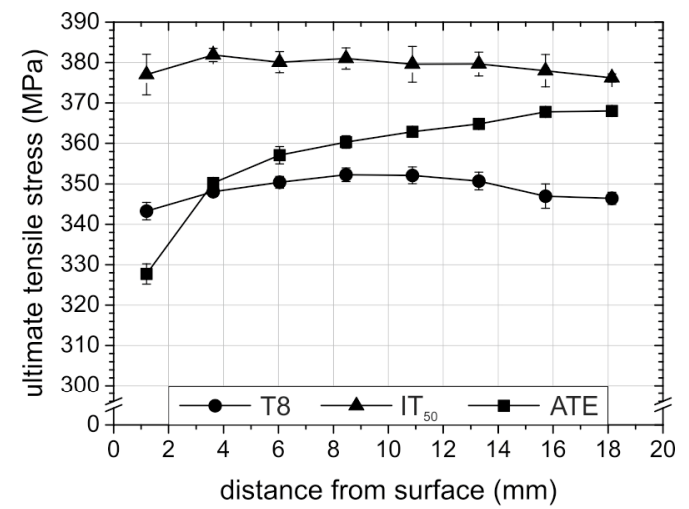

(b)

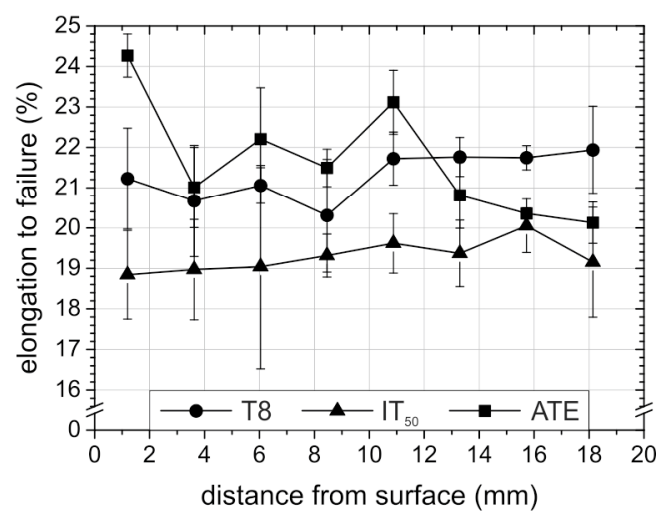

(d)

Figure 7. Overview of the tensile properties of the optimized conditions T8 (RT-extrusion and peak aged, circles), IT $_{50}$ (IT-extrusion and aged for $50 \mathrm{~min}$, triangles) and ATE (AT-extrusion, as-extruded, squares) as a function of distance from the surface. (a) Yield strength; (b) ultimate tensile strength; (c) uniform elongation; and, (d) elongation to failure. 


\section{Summary and Conclusions}

We have studied the effect of extrusion temperature on the aging behavior and the resulting mechanical properties of cylindrical rods that were extruded from cast billets of an AA6060 aluminum alloy at room temperature (RT), at $120{ }^{\circ} \mathrm{C}(\mathrm{IT})$, and at $170{ }^{\circ} \mathrm{C}(\mathrm{AT})$, respectively. As discussed in our previous study [15], cold and warm extrusion of this alloy results in heterogeneous microstructures with rather coarse elongated grains in the center areas, and a partially ultrafine-grained pancake microstructure in the surface layers, of the extrudates. Due to the different processing temperatures and the gradient of plastic straining between core and surface of the extrudates, various stages of the precipitation sequence were observed in the as-extruded material. We found that the extent of strain hardening and dynamic precipitation significantly alter the effects of a subsequent artificial aging. While AT-extrusion fully exploits the effects of dynamic aging-resulting, e.g., in the lowest processing time- it leads to a high, but heterogeneous strength with the lowest ductility (uniform elongation). Processing at RT with a subsequent short-time aging for $50 \mathrm{~min}$ at $170{ }^{\circ} \mathrm{C}$ offers an evenly distributed strength at a similar level and a higher ductility. When considering these parameters, the best mechanical properties were obtained by extrusion at IT and short-time aging (50 min), which offers an increase of strength by about $31 \%$ at a reduction of aging time by $97.5 \%$.

Acknowledgments: The authors gratefully acknowledge funding by the German Research Foundation (Deutsche Forschungsgemeinschaft, DFG) in the framework of the Collaborative Research Center SFB 692 (projects T4 and Z2). We also thank Marcus Böhme and Anne Schulze for support with the electron microscopy investigations.

Author Contributions: Nadja Berndt and Philipp Frint conceived and designed the experiments. Nadja Berndt performed and analyzed the experiments, prepared the figures and drafted the manuscript. Philipp Frint and Martin F.-X. Wagner conceived of the study, discussed the results and analysis and helped writing the manuscript.

Conflicts of Interest: The authors declare no conflict of interest.

\section{References}

1. Sheppard, T. Extrusion of Aluminium Alloys; Kluwer Academic Publishers: Dordrecht, The Netherlands, 1999; ISBN 978-0412590702.

2. Atkinson, A.; Taylor, R.I. The diffusion of Ni in the bulk and along dislocations in NiO single crystals. Philos. Mag. A 1979, 39, 581-595. [CrossRef]

3. Staab, T.E.M.; Haaks, M.; Modrow, H. Early precipitation stages of aluminum alloys-The role of quenched-in vacancies. Appl. Surf. Sci. 2008, 255, 132-135. [CrossRef]

4. Frint, P.; Hockauf, M.; Halle, T.; Strehl, G.; Lampke, T.; Wagner, M.F.-X. Microstructural Features and Mechanical Properties after Industrial Scale ECAP of an Al-6060 Alloy. Mater. Sci. Forum 2011, 667-669, 1153-1158. [CrossRef]

5. Frint, P.; Hockauf, M.; Halle, T.; Wagner, M.F.-X.; Lampke, T. The role of backpressure during large scale equal-channel angular pressing. Materwiss. Werkst. 2012, 43, 668-672. [CrossRef]

6. Frint, S.; Hockauf, M.; Frint, P.; Wagner, M.F.-X. Scaling up Segal's principle of Equal-Channel Angular Pressing. Mater. Des. 2016, 97, 502-511. [CrossRef]

7. Valiev, R.Z.; Langdon, T.G. Principles of equal-channel angular pressing as a processing tool for grain refinement. Prog. Mater. Sci. 2006, 51, 881-981. [CrossRef]

8. Sha, G.; Wang, Y.B.; Liao, X.Z.; Duan, Z.C.; Ringer, S.P.; Langdon, T.G. Influence of equal-channel angular pressing on precipitation in an Al-Zn-Mg-Cu alloy. Acta Mater. 2009, 57, 3123-3132. [CrossRef]

9. Roven, H.J.; Liu, M.; Werenskiold, J.C. Dynamic precipitation during severe plastic deformation of an Al-Mg-Si aluminium alloy. Mater. Sci. Eng. A 2008, 483-484, 54-58. [CrossRef]

10. Gubicza, J.; Schiller, I.; Chinh, N.Q.; Illy, J.; Horita, Z.; Langdon, T.G. The effect of severe plastic deformation on precipitation in supersaturated Al-Zn-Mg alloys. Mater. Sci. Eng. A 2007, 460-461, 77-85. [CrossRef]

11. Cai, M.; Field, D.P.; Lorimer, G.W. A systematic comparison of static and dynamic ageing of two $\mathrm{Al}-\mathrm{Mg}-\mathrm{Si}$ alloys. Mater. Sci. Eng. A 2004, 373, 65-71. [CrossRef]

12. Hirosawa, S.; Hamaoka, T.; Horita, Z.; Lee, S.; Matsuda, K.; Terada, D. Methods for designing concurrently strengthened severely deformed age-hardenable aluminum alloys by ultrafine-grained and precipitation hardenings. Metall. Mater. Trans. A 2013, 44, 3921-3933. [CrossRef] 
13. Hockauf, M.; Meyer, L.W.; Zillmann, B.; Hietschold, M.; Schulze, S.; Krüger, L. Simultaneous improvement of strength and ductility of $\mathrm{Al}-\mathrm{Mg}-\mathrm{Si}$ alloys by combining equal-channel angular extrusion with subsequent high-temperature short-time aging. Mater. Sci. Eng. A 2009, 503, 167-171. [CrossRef]

14. Kim, W.J.; Kim, J.K.; Park, T.Y.; Hong, S.I.; Kim, D.I.; Kim, Y.S.; Lee, J.D. Enhancement of Strength and Superplasticity in a $6061 \mathrm{Al}$ Alloy Processed by Equal-Channel-Angular-Pressing. Metall. Mater. Trans. A 2002, 33, 3155-3164. [CrossRef]

15. Berndt, N.; Frint, P.; Böhme, M.; Wagner, M.F.-X. Microstructure and Mechanical Properties of an AA6060 Aluminum Alloy after Cold and Warm Extrusion. Mater. Sci. Eng. A 2017, 707, 717-724. [CrossRef]

16. Frint, P.; Wagner, M.F.-X.; Weber, S.; Seipp, S.; Frint, S.; Lampke, T. An experimental study on optimum lubrication for large-scale severe plastic deformation of aluminum-based alloys. J. Mater. Process. Technol. 2017, 239, 222-229. [CrossRef]

(C) 2018 by the authors. Licensee MDPI, Basel, Switzerland. This article is an open access article distributed under the terms and conditions of the Creative Commons Attribution (CC BY) license (http://creativecommons.org/licenses/by/4.0/). 